\title{
Distinct Transcriptomic Reprogramming in the Wheat Stripe Rust Fungus During the Initial Infection of Wheat and Barberry
}

\author{
Jing Zhao, ${ }^{1,2,+}$ Wanlu Duan, ${ }^{1}$ Yiwen Xu, ${ }^{1}$ Ce Zhang, ${ }^{1}$ Long Wang, ${ }^{1}$ Jierong Wang, ${ }^{1}$ Song Tian, ${ }^{1}$ \\ Guoliang Pei, ${ }^{2}$ Gangming Zhan, ${ }^{1,2}$ Hua Zhuang, ${ }^{1,2}$ Jie Zhao, ${ }^{1,2}$ and Zhensheng Kang ${ }^{1,2,+}$ \\ ${ }^{1}$ College of Plant Protection, Northwest A\&F University, Yangling, Shaanxi, People's Republic of China \\ ${ }^{2}$ State Key Laboratory of Crop Stress Biology for Arid Areas, Northwest A\&F University, Yangling, Shaanxi, People's Republic \\ of China
}

Accepted 28 October 2020.

Puccinia striiformis f. sp. tritici is the causal agent of wheat stripe rust that causes severe yield losses all over the world. As a macrocyclic heteroecious rust fungus, it is able to infect two unrelated host plants, wheat and barberry. Its urediniospores infect wheat and cause disease epidemic, while its basidiospores parasitize barberry to fulfill the sexual reproduction. This complex life cycle poses interesting questions on the different mechanisms of pathogenesis underlying the infection of the two different hosts. In the present study, transcriptomes of $P$. striiformis f. sp. tritici during the initial infection of wheat and barberry leaves were qualitatively and quantitatively compared. As a result, 142 wheat-specifically expressed genes (WEGs) were identified, which was far less than the 2,677 barberry-specifically expressed genes (BEGs). A larger proportion of evolutionarily conserved genes were observed in BEGs than that in WEGs, implying a longer history of the interaction between $\boldsymbol{P}$. striiformis f. sp. tritici and barberry. Additionally, $P$. striiformis f. sp. tritici differentially expressed genes (DEGs) between wheat at 1 and 2 days postinoculation (dpi) and barberry at 3 and 4 dpi were identified by quantitative analysis. Gene Ontology analysis of these DEGs and expression patterns of $P$. striiformis f. sp. tritici pathogenic genes, including those encoding candidate secreted effectors, cell wall-degrading enzymes, and nutrient transporters, demonstrated that urediniospores and basidiospores exploited distinct strategies to overcome host defense systems. These results represent the first analysis of the $P$. striiformis f. sp.

The data that support the findings of this study are openly available in NCBI Sequence Read Archive, reference number PRJNA637808.

${ }^{\dagger}$ Corresponding authors: J. Zhao; zhaojing@nwsuaf.edu.cn and Z. Kang; kangzs@nwsuaf.edu.cn

Funding: This work was funded by the National Key Research and Development Program of China (number 2018YFD0200402), Research Funds for the Central Universities of China (number 2452017405), National Transgenic Key Project of China (number 2016ZX08002-01), and Natural Science Basic Research Plan in Shaanxi Province of China (number 2019JCW-18).

*The $\boldsymbol{e}$-Xtra logo stands for "electronic extra" and indicates that supplementary figures and tables are published online.

The author(s) declare no conflict of interest.

(c) (1) () $\odot$ Copyright $\odot 2021$ The Author(s). This is an open access article (c) (1) (3) () distributed under the CC BY-NC-ND 4.0 International license. tritici transcriptome in barberry and contribute to a better understanding of the evolutionary processes and strategies of different types of rust spores during the infection process on different hosts.

Keywords: barberry, basidiospore, host specificity, transcriptome, urediniospore, wheat stripe rust

Rust fungi (Pucciniales) are the largest group of plantpathogenic fungi, with more than 8,000 described species (Aime et al. 2017). Puccinia striiformis f. sp. tritici, the causal agent of wheat stripe rust, is among the most important pathogens on wheat and can cause severe yield losses. As a macrocyclic heteroecious rust fungus, $P$. striiformis $\mathrm{f}$. sp. tritici has five morphologically and functionally different spore forms and requires two specific but unrelated host plants to complete its life cycle (Zhao et al. 2016). In spring, teliospores overwintering on wheat debris germinate and produce basidiospores. Basidiospores infect barberry and form receptive hyphae and pycniospores on the upper surface of the barberry leaves. Upon fertilization of receptive hyphae by pycniospores, a dicaryotic mycelium develops that ultimately forms aeciospores on the lower surface of the barberry leaves. Aeciospores then infect wheat and produce asexual urediniospores that can infect wheat in repeated cycles and cause disease epidemics. At the late growing season of wheat, teliospores are produced, which allow $P$. striiformis $\mathrm{f}$. sp. tritici to survive the unfavorable summer and winter seasons.

This survival strategy of $P$. striiformis f. sp. tritici poses interesting questions regarding the mechanisms of pathogenesis as well as nutrient uptake underlying the infection of two botanically unrelated host plants. Although having the same genetic background, urediniospores and basidiospores specifically infect wheat and barberry, respectively. In addition, different mechanisms are applied to penetrate host tissues. Urediniospores infect wheat through stomata while basidiospores infect barberry through direct penetration of epidermal cells by appressorium (Jiao et al. 2017). It was therefore suggested that transcriptomic reprogramming in these two types of spores might account for the $P$. striiformis $\mathrm{f}$. sp. tritici capacity of infecting two different hosts, especially at the initial stage of infection. In recent years, the transcriptomic profiling of cereal rust fungi and wheat interactions have been extensively studied (Chen et al. 2013; Dobon et al. 2016; Garnica et al. 2013; Rutter et al. 2017; Yadav et al. 2016). Although mainly converging on 
the host aspect, these studies provide valuable information for deciphering rust pathogenicity and wheat immune response. However, transcriptomic studies on interactions between cereal rust fungi and their alternate hosts are less mentioned at present.

In order to successfully colonize wheat, $P$. striiformis $\mathrm{f}$. $\mathrm{sp}$. tritici utilizes a set of pathogenicity-related genes and mechanisms to defeat the plant immune system and acquire nutrients to enable further growth and propagation. Previous studies have identified many $P$. striiformis $\mathrm{f}$. sp. tritici candidate secreted effector protein (CSEP) genes by haustoria isolation and sequencing (Cantu et al. 2013; Upadhyaya et al. 2015). Recently, a number of $P$. striiformis $\mathrm{f}$. sp. tritici effectors playing critical roles during the infection of wheat have been identified and functionally characterized (Cheng et al. 2015, 2017; Liu et al. 2016; Qi et al. 2019a; Wang et al. 2017; Xu et al. 2019; Yang et al. 2020; Zhao et al. 2018). For example, GSRE1 is a glycineserine-rich effector that can suppress host immunity through targeting and blocking the nuclear localization of wheat transcription factor TaLOL2, a positive regulator of wheat reactive oxygen species (ROS) production (Qi et al. 2019a). Another important $P$. striiformis $\mathrm{f}$. sp. tritici effector is $P$. striiformis $\mathrm{f}$. sp. tritici_12806, which facilitates rust infection by interfering with the function of chloroplasts, such as electron transport, photosynthesis, and chloroplast-derived ROS production (Xu et al. 2019). Recent studies have shown that the sexual cycle of $P$. striiformis f. sp. tritici on barberry is responsible for the observed frequent virulence variations and the generation of new races of the pathogen (Zhao et al. 2016). However, very little is known about the specific mechanisms of $P$. striiformis f. sp. tritici to infect its alternate host barberry.

In the present study, we analyzed and compared the global transcript profiles of $P$. striiformis f. sp. tritici during infection of two different hosts. Sets of genes that are specifically expressed in either wheat or barberry were identified. Expression levels of $P$. striiformis $\mathrm{f}$. sp. tritici effector genes and other genes involved in pathogenicity (such as plant cell walldegrading genes and nutrient transporter genes) in the initial stage of wheat and barberry infection were quantified and analyzed. Our data represents the first report of the transcriptome of $P$. striiformis f. sp. tritici during the infection of barberry. This work provides a model to understand the evolutionary processes and strategies of different types of rust spores during the infection process on different hosts.

\section{RESULTS}

Histological analyses of $\boldsymbol{P}$. striiformis f. sp. tritici infection of barberry and wheat.

$P$. striiformis f. sp. tritici basidiospores and urediniospores use different ways to infect the respective hosts. Urediniospores germinate on wheat leaves and enter plant tissue through stomata. By contrast, germinated basidiospores penetrate barberry leaf tissue directly through the epidermis (Jiao et al. 2017). To identify an appropriate timepoint for a comparison of the two types of infection, we compared the infection processes of basidiospores and urediniospores of $P$. striiformis f. sp. tritici isolate CYR32 by histological observation (Fig. 1A). In wheat leaves inoculated by urediniospores, the formation of haustoria can be observed at 1 day postinoculation (dpi), followed by the formation of the secondary hyphae at $2 \mathrm{dpi}$. The penetration frequency for urediniospores raised from $17.0 \%$ at 1 dpi to $24.3 \%$ at 2 dpi, then remained around $26 \%$ at 3,4 , and 5 dpi (Fig. 1B). The infection process emanating from basidiospores on barberry seems to be more slowly. The ovate intraepidermal vesicles (OIVs) were not observed until 3 dpi and the secondary hyphae formed at $4 \mathrm{dpi}$ (Fig. 1A). The penetration frequency for basidiospores raised from $11.1 \%$ at 3 dpi to $16.6 \%$ at 4 dpi and

was held at $17.3 \%$ at $5 \mathrm{dpi}$ (Fig. 1B). Therefore, wheat leaves at 2 dpi and barberry leaves at 4 dpi were selected for qualitative comparison. These two timepoints represent early stages of infection by urediniospores and basidiospores when a parasitic relationship between $P$. striiformis f. sp. tritici and the host plant has just been established.

\section{Transcriptomes of $\boldsymbol{P}$. striiformis f. sp. tritici} during infection of wheat and barberry.

To clarify the different mechanisms deployed by urediniospores and basidiospores during the infection process of wheat and barberry, transcriptomes of both interactions were compared. Two P. striiformis f. sp. tritici isolates, CYR32 and V26, were inoculated on wheat and barberry leaves. Then wheat leaf samples at 2 dpi and barberry leaf samples at 4 dpi were collected. Since the fungal RNA at the early stage of infection represents only a small fraction of the total RNA from infected leaves, we constructed normalized complementary DNA (cDNA) libraries to increase the proportion of pathogen RNA, which enabled us to detect expressed fungal genes more readily. Data from the normalized library were used for qualitative comparison of expressed genes of two P. striiformis f. sp. tritici isolates in wheat and barberry. Meanwhile, barberry leaf
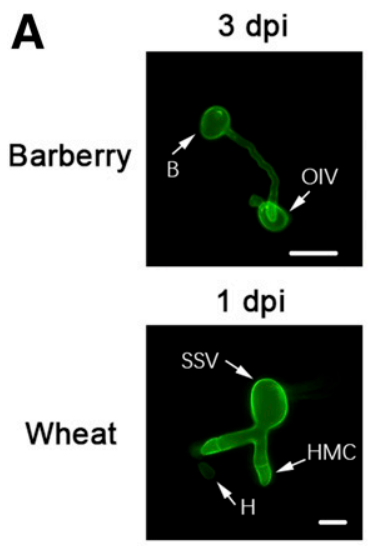

B

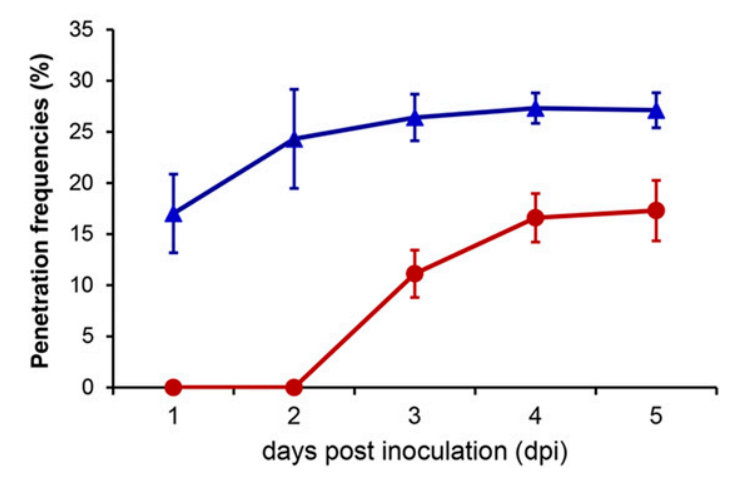

Fig. 1. Infection processes of Puccinia striiformis $\mathrm{f}$. sp. tritici basidiospores and urediniospores on barberry and wheat. A, Microscopic observation of development processes of Puccinia strifformis f. sp. tritici basidiospores and urediniospores on barberry and wheat. B, Penetration frequencies of $P$. striiformis f. sp. tritici basidiospores and urediniospores on barberry and wheat during the early stage of infection. Penetration frequencies for urediniospores on wheat leaves (blue) represent the percentage of germinated spores penetrating the mesophyll cells and forming haustoria. Penetration frequencies for basidiospores on barberry leaves (red) represent the percentage of germinated spores penetrating into epidermal cells and forming an ovate intraepidermal vesicle (OIV). $\mathrm{B}=$ Basidiospore, $\mathrm{SH}=$ secondary hyphae, $\mathrm{H}=$ haustorium, $\mathrm{SSV}=$ substoma vesicle, $\mathrm{HMC}=$ haustorial mother cell. Bars $=10 \mu \mathrm{m}$. Each datapoint represents the mean \pm standard deviation of three replicates (leaves infected by $P$. striiformis f. sp. tritici isolate CYR32). 
samples from 3 and $4 \mathrm{dpi}$ as well as wheat leaf samples from 1 and 2 dpi were collected, and nonnormalized libraries were constructed for quantitative analysis of transcriptional levels for $P$. striiformis f. sp. tritici genes during the early stage of infection of two hosts.

Following quality filtering and data trimming, an average of 44.6 and 65 million high-quality reads per sample were produced for normalized and nonnormalized samples, respectively (Table 1; Supplementary Table S1). All these reads were mapped onto the PST-CY32 reference genome (Zheng et al. 2013). Since some reads that mapped to the reference genome did not align to predicted exons, we used our transcriptome data to generate an updated set of annotations, using the software Cufflinks and the RABT (reference annotation based transcript) assembly pipeline (Roberts et al. 2011; Trapnell et al. 2012), which led to the annotation of another 2,712 genes (Supplementary Table S2) in addition to the 26,832 genes predicted from the reference genome. With the increase of sequencing depth, each sample reached a plateau in the saturation curves independently of the isolates, host, or timepoints (Supplementary Fig. S1), indicating a sufficient sequencing depth to cover a full transcriptome for all the samples.

For normalized samples, the percentage of reads aligned to the $P$. striiformis $\mathrm{f}$. sp. tritici genome were $14.47 \%$ (CYR32) and $19.79 \%$ (V26) for wheat leaves and $13.05 \%$ (CYR32) and $9.80 \%$ (V26) for barberry leaves (Table 1). Among the 29,544 genes, transcripts of 18,328 genes $(62.0 \%)$ were detected (with at least one read assigned). For isolate CYR32, 17,180 and 11,281 genes were found to be expressed in barberry and wheat, respectively. Similarly, for isolate V26, 14,032 and 10,550 $P$. striiformis f. sp. tritici genes were found to be expressed in barberry and wheat, respectively (Fig. 2A; Supplementary Table S3). These results demonstrated that many more $P$. striiformis f. sp. tritici genes were expressed during the infection of barberry than that of wheat. In addition, 8,277 genes were detected in all samples, indicating their essential roles in $P$. striiformis $\mathrm{f}$. sp. tritici infection of both hosts.

Compared with normalized samples, the percentages of reads mapped to $P$. striiformis f. sp. tritici genome for nonnormalized samples were apparently much lower (ranged from 0.55 to $1.25 \%$ ), and few genes were detected, as well (Supplementary Table S1). Similarly, there were still more gene transcripts detected in barberry than that in wheat, which was consistent with the results from the normalized samples.

\section{Host-specifically expressed genes \\ of $P$. striiformis f. sp. tritici during the onset of pathogenesis in wheat or barberry.}

Expression levels from the normalized samples were used to characterize host-specifically expressed genes that are exclusively expressed in wheat or barberry at the early stage of infection. To this end, a threshold of transcripts per million (TPM) value above 2.0 in one host while below 2.0 in another host and their ratio above 5.0 was defined for qualitative identification. Then, the analysis was performed for CYR32 and V26 separately and the intersection for two isolates were obtained. Finally, 142 wheat-specifically expressed genes (WEGs) were identified, which is far less than the 2,677

Table 1. RNA-based sequence alignments against Puccinia striiformis f. sp. tritici CYR32 reference genome for normalized samples

\begin{tabular}{|c|c|c|c|c|}
\hline \multirow[b]{2}{*}{ Sample } & \multicolumn{2}{|c|}{ Barberry infected by } & \multicolumn{2}{|c|}{ Wheat infected by } \\
\hline & CYR32 & V26 & CYR32 & V26 \\
\hline Total reads & $47,893,032$ & $49,554,386$ & $48,957,451$ & $32,164,691$ \\
\hline Total mapped & $6,250,446(13.05 \%)$ & 4,856,748 (9.80\%) & $7,081,825(14.47 \%)$ & $6,365,045(19.79 \%)$ \\
\hline Total unmapped & $41,642,586(86.95 \%)$ & $44,697,638(90.20 \%)$ & $41,875,626(85.53 \%)$ & $25,799,646(80.21 \%)$ \\
\hline Unique match & $782,080(1.63 \%)$ & $398,277(0.80 \%)$ & $360,634(0.74 \%)$ & $150,279(0.47 \%)$ \\
\hline Multiple match & $5,468,366(11.42 \%)$ & $4,458,471(9.00 \%)$ & $6,721,191(13.73 \%)$ & $6,214,766(19.32 \%)$ \\
\hline Perfect match & $5,621,223(11.74 \%)$ & $4,515,399(9.11 \%)$ & $6,584,063(13.45 \%)$ & $5,745,820(17.86 \%)$ \\
\hline$\leq 5$-bp mismatch & $591,367(1.23 \%)$ & $316,156(0.64 \%)$ & $485,213(0.99 \%)$ & $501,987(1.56 \%)$ \\
\hline Unique matched genes & 17,180 & 14,032 & 11,285 & 10,554 \\
\hline
\end{tabular}

A

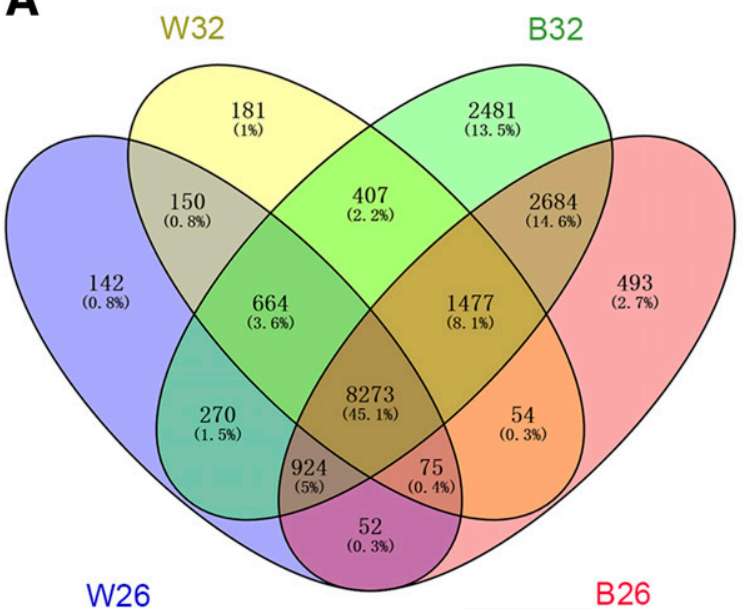

B

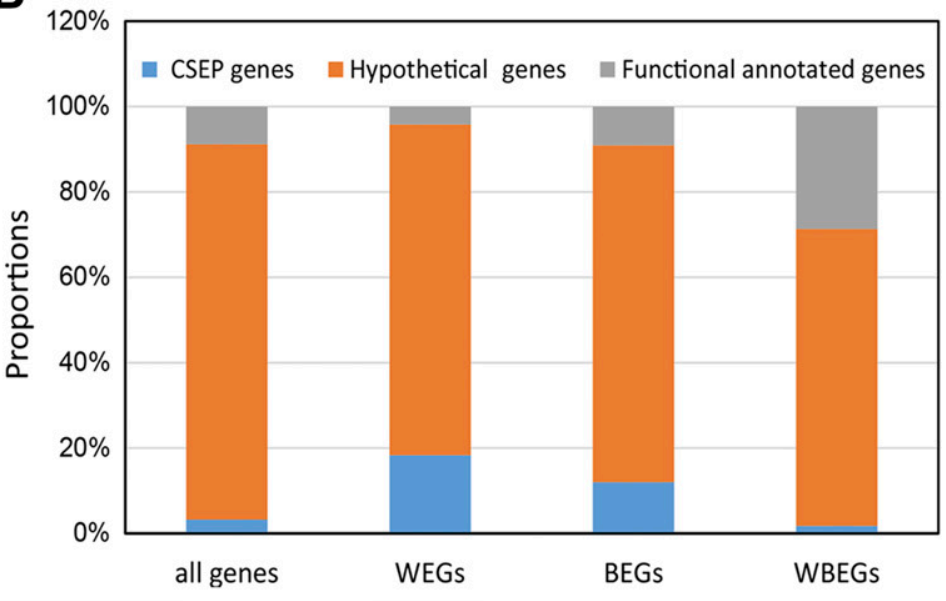

Fig. 2. Identifying Puccinia striiformis f. sp. tritici genes specifically expressed in wheat or barberry. A, Venn diagram depicting numbers of Puccinia striiformis f. sp. tritici genes detected from normalized samples. W32 and B32 represent wheat and barberry leaves infected by isolate CYR32; W26 and B26 represent wheat and barberry leaves infected by isolate V26. B, The proportion of candidate secreted effector protein (CSEP) genes, hypothetical genes and functional annotated genes in wheat-specifically expressed genes (WEGs), barberry-specifically expressed genes (BEGs), and wheat-barberry commonly expressed genes (WBEGs). 
barberry-specifically expressed genes (BEGs) and 1,646 wheatbarberry commonly expressed genes (WBEGs) identified (Supplementary Table S3).

Effectors are known as key pathogenic components that facilitate infection by modulating plant immunity and reprogramming host cell metabolisms. Among the 953 CSEP genes, 26 wheat-specifically expressed effector genes (WEEs) were identified. Meanwhile 321 BEGs and 29 WBEGs were identified as barberry-specifically expressed effector genes (BEEs) and wheat-barberry commonly expressed effector genes (WBEEs), respectively. Despite the small number of WEEs, they account for a relatively bigger proportion of WEGs $(18.3 \%)$ than BEEs and WBEEs, which account for $12.0 \%$ and $1.8 \%$ of WEGs and WBEGs. In contrast, a higher percentage of functionally annotated genes were found in WBEGs $(28.7 \%)$ than that in BEGs $(9.1 \%)$ or WEGs $(4.2 \%)$ (Fig. $2 \mathrm{~B})$.

\section{Genes specifically expressed in wheat are "younger" than those in barberry.}

As a high proportion of functional annotated genes in BEGs, we speculated that these genes were evolutionary conserved among basidiomycetes. To test this hypothesis, we identified orthologs of host specifically expressed genes from nine basidiomycetes, namely, Puccinia striiformis f. sp. tritici PST-78, $P$. graminis f. sp. tritici, $P$. triticina $1-1 \mathrm{BBBD}$ race 1 , Uromyces viciae-fabae, Melamspora larici-populina, Cronartium quercuum f. sp. fusiforme, Naiadella fluitans ATCC 64713 v1.0, Mixia osmundae IAM, and Ustilago maydis 521. Orthologs to BEGs were identified in a frequency of 40.12 to $89.65 \%$. While, many fewer orthologs for WEGs were identified. For example, only $21.13 \%$ of the WEGs have orthologs in Ustilago maydis, which was about one-half of that of BEGs (Table 2). In conclusion, genes specifically expressed in barberry tended to be evolutionarily conserved while there were larger proportions of young genes specifically expressed in wheat.

\section{Identification of $P$. striiformis f. sp. tritici differentially expressed genes (DEGs) during infection \\ of wheat and barberry.}

Expression levels from the nonnormalized samples were used for a quantitative comparison of expression patterns of $P$. striiformis f. sp. tritici genes in wheat and barberry. In total, 1,968 DEGs of $P$. striiformis $\mathrm{f}$. sp. tritici during the infection of wheat at 1 and 2 dpi and barberry at 3 and 4 dpi were identified (Fig. 3; Supplementary Table S4). Among them, there were 1,410 DEGs for samples from barberry at 3 dpi versus samples from wheat at $1 \mathrm{dpi}$, and 1,001 DEGs for barberry at $4 \mathrm{dpi}$ versus wheat at $2 \mathrm{dpi}$. In total, there were 1,234 genes abundant in barberry at 3 or $4 \mathrm{dpi}$, while 734 genes were abundant in wheat at 1 or 2 dpi. However, there were no significant differences of expression levels between 3 and 4 dpi in barberry, as well as of expression levels between 1 and 2 dpi in wheat, suggesting a gradual and consistent course of infection.

Puccinia striiformis $\mathrm{f}$. sp. tritici DEGs between hosts were categorized into functional classes using Gene Ontology (GO) to identify specific terms they were involved in (Supplementary Table S5). As shown in Figure 4, DEGs abundant in barberry at 3 or 4 dpi were enriched in hydrolase activity (acting on carbonnitrogen bonds) (GO:0016810), FMN binding (GO:0010181), carbohydrate metabolic process (GO:0005975), oxidoreductase activity (GO:0016491), and calcium ion binding(GO:0005509). In contrast, DEGs abundant in wheat at 1 or 2 dpi were overrepresented by hydrolase activity (hydrolyzing $O$-glycosyl compounds) (GO:0004553), carbohydrate metabolic process (GO:0005975), channel activity (GO:0015267), substituted mannan metabolic process (GO:0006080), mannan endo-1,4$\beta$-mannosidase activity (GO:0016985), and chromatin remodeling (GO:0006338).

An analysis of the Kyoto Encyclopedia of Genes and Genomes (KEGG) pathway was also performed to identify metabolic pathways involving $P$. striiformis f. sp. tritici DEGs (Supplementary Table S6; Supplementary Fig. S4). As a result, DEGs abundant in barberry were mainly enriched in starch and sucrose metabolism (ko00500), melanogenesis (ko04916), cAMP signaling pathway (ko04024), aldosterone synthesis and secretion (ko04925), and Kaposi sarcoma-associated herpesvirus infection (ko05167); and DEGs abundant in wheat were mainly enriched in the mitogen-activated protein kinase signaling pathway (ko04011), transcription factors (BR:ko03000), protein phosphatases and associated proteins (BR:ko01009), and pentose and glucuronate interconversions (ko00040).

\section{Expression profile of CSEP repertoires \\ in wheat and barberry and six BEEs suppress \\ $B A X-i n d u c e d$ cell death in tobacco.}

The expression patterns of 230 CSEP DEGs were clustered (Fig. 5; Supplementary Table S4). Apparently, most of the CSEP genes abundant in wheat fall into clade I, representing genes with higher expression levels in wheat at 1 or 2 dpi than that in barberry at 3 or 4 dpi. Unsurprisingly, nearly all WEEs (24 of 26) were identified as CSEP DEGs and were attributed to clade I, and there were seven CSEP DEGs abundant in wheat that belonged to WBEEs, because of their absolute higher expression in both hosts. Similarly, clade II contains all of the 174 CSEP DEGs abundant in barberry, in which 151 genes belonged to 321 BEEs.

One of the most important functions of pathogen effectors is to suppress host immune responses, such as the hypersensitive cell death. A number of $P$. striiformis f. sp. tritici effectors identified from $P$. striiformis f. sp. tritici-wheat interaction have been proven to function in suppression of wheat cell death (Qi et al. 2019a; Xu et al. 2019). Since no obvious cell death of

Table 2. Number and proportion of orthologs identified from nine basidiomycetes for wheat-specifically expressed genes (WEGs) and barberry-specifically expressed genes (BEGs)

\begin{tabular}{|c|c|c|c|c|}
\hline \multirow[b]{2}{*}{ Species } & \multicolumn{2}{|c|}{ WEGs (142) } & \multicolumn{2}{|c|}{ BEGs (2677) } \\
\hline & No. of hits & Proportion (\%) & No. of hits & Proportion (\%) \\
\hline Ustilago maydis & 30 & 21.13 & 1,074 & 40.12 \\
\hline Mixia osmundae & 30 & 21.13 & 1,186 & 44.30 \\
\hline Naiadella fluitans & 38 & 26.76 & 1,231 & 45.98 \\
\hline Melamspora larici-populina & 55 & 38.73 & 1,535 & 57.34 \\
\hline Cronartium quercuum f. sp. fusiforme & 59 & 41.55 & 1,554 & 58.05 \\
\hline Uromyces viciae-fabae & 67 & 47.18 & 1,679 & 62.72 \\
\hline Puccinia triticina & 89 & 62.68 & 1,991 & 74.37 \\
\hline P. graminis f. sp. tritici & 91 & 64.08 & 2,168 & 80.99 \\
\hline P. striiformis f. sp. tritici (PST-78) & 118 & 83.10 & 2,400 & 89.65 \\
\hline
\end{tabular}


barberry leaves was observed during the $P$. striiformis f. sp. tritici infection, we speculated that those BEEs might play similar roles in barberry as in wheat. To validate their role in the suppression of cell death, 60 BEEs were transiently expressed in tobacco together with BAX, which has been shown to be an inducer of plant cell death. Finally, six BEEs were proven to inhibit BAX-induced cell death in tobacco (Fig. 6), suggesting their critical role in impairing the plant immune system.

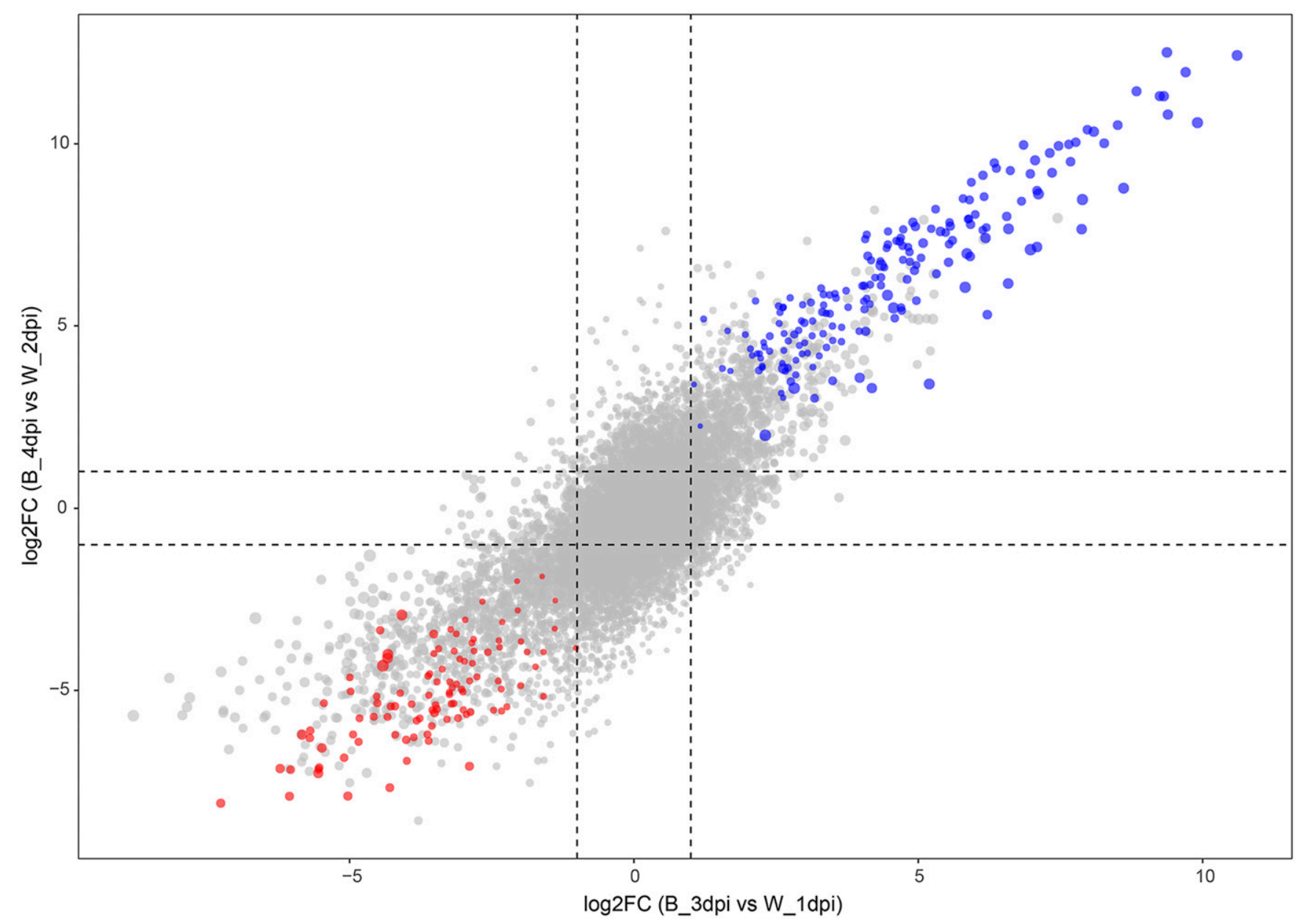

Fig. 3. Puccinia striiformis f. sp. tritici genes differentially expressed in wheat or barberry. Scatter plot representing the relative gene expression levels of 1,968 Puccinia striiformis f. sp. tritici differentially expressed genes (DEGs) in wheat and barberry. P. striiformis f. sp. tritici gene expression levels in barberry at 3 days postinoculation (dpi) (B_3dpi) versus in wheat at 1 dpi (W_1dpi) were plotted on the $x$ axis, and gene expression levels in barberry at 4 dpi (B_4dpi) versus in wheat at 2 dpi (W_2dpi) were plotted on the $y$ axis. Blue and red dots represent DEGs abundant in barberry and wheat, respectively. The dot color from light to deep indicates the adjusted $P$ value from big to small.
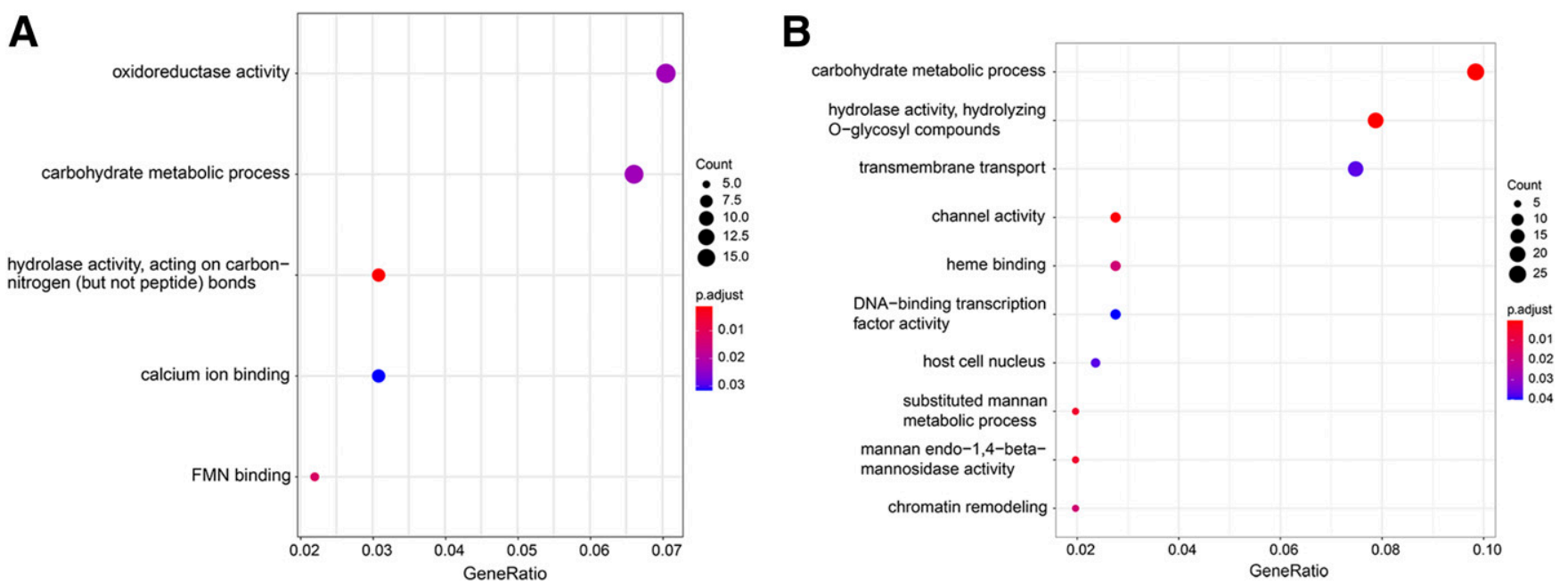

Fig. 4. Gene Ontology (GO) enrichment analysis of Puccinia striiformis f. sp. tritici differentially expressed genes (DEGs) between wheat and barberry. A, Enrichment analysis of GO terms for Puccinia striiformis f. sp. tritici DEGs abundant in wheat and $\mathbf{B}$, abundant in barberry $(P<0.05$ with false discovery rate correction). The R package of clusterProfiler was used for enrichment analysis (Yu et al. 2012). 
Expression patterns of host cell wall-degrading genes between wheat and barberry.

Plant cuticle and cell wall are the first barriers to block the infection of $P$. striiformis $\mathrm{f}$. sp. tritici. To achieve successful penetration, $P$. striiformis $\mathrm{f}$. sp. tritici releases a set of cell-wall and cuticle-degrading enzymes, such as pectinase, cellulase, hemicellulose, and cutinase. The genes encoding these enzymes were identified and their expression levels were compared during the infection of wheat and barberry (Fig. 7A). Seven genes encoding pectinases were identified and all of them were expressed in barberry, while they were nearly undetectable in wheat leaves. Among seven genes encoding cellulase, three had little or no expression in both hosts, and four were highly expressed in barberry and one was moderately expressed in wheat. For the ten genes that encode hemicellulases, all were expressed in barberry at moderate or low levels while none of them were detected in the wheat. Remarkably, among the eight genes encoding secreted cutinases, two were highly expressed in

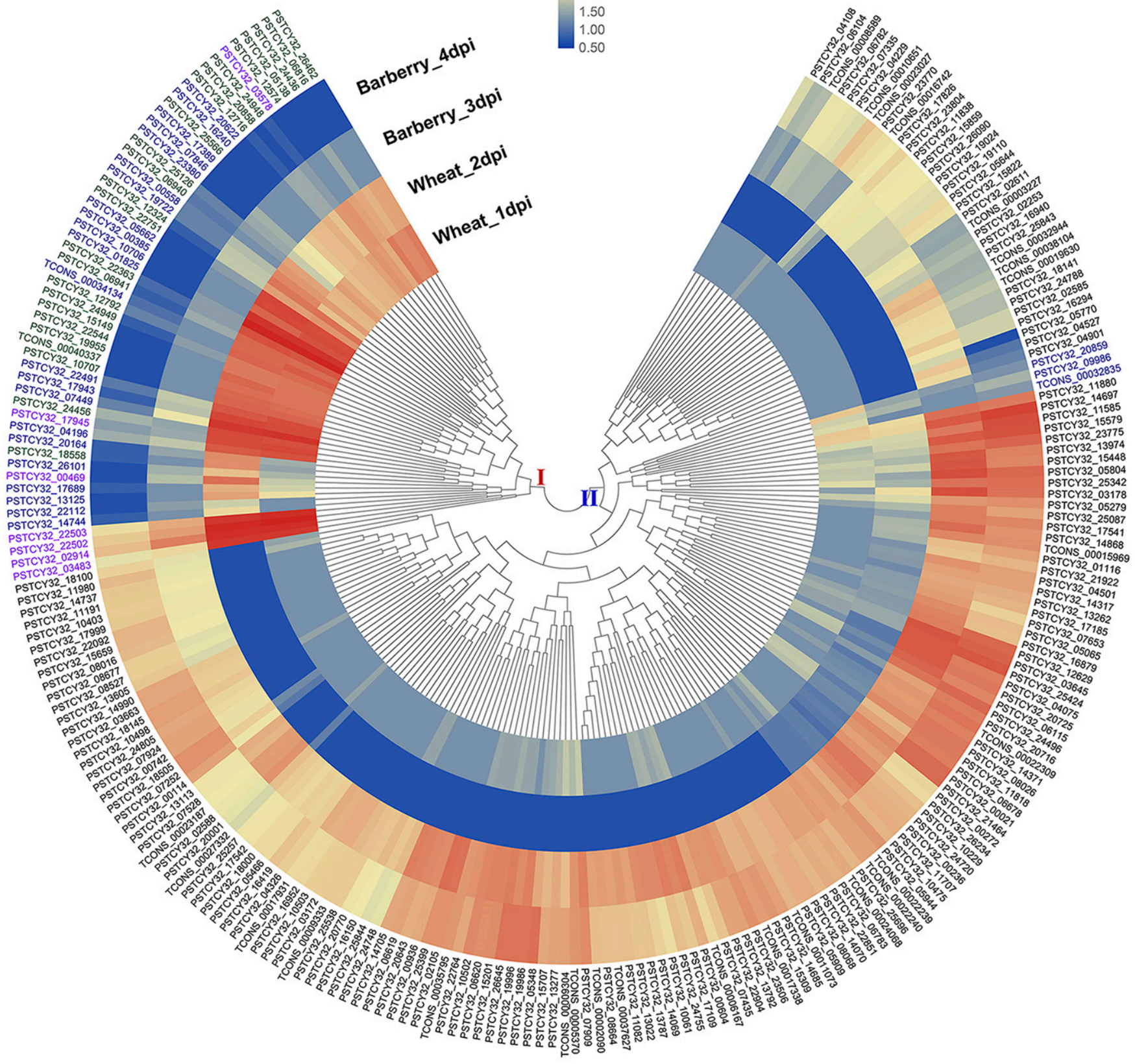

Fig. 5. Heatmaps of gene expression showing Puccinia striiformis f. sp. tritici candidate secreted effector protein (CSEP) genes differentially expressed in wheat and barberry. Hierarchical clustering of the expression levels (transcript per million values after the logarithm) of Puccinia striiformis f. sp. tritici CSEP genes differentially expressed in wheat and barberry showing two distinct clades. Clade I represents effector genes with higher expression levels in wheat at 1 or 2 days postinoculation (dpi) compared with that in barberry at 3 or 4 dpi. Clade II contains most differentially expressed genes (DEGs) abundant in barberry. DEGs abundant in wheat that were identified as WEEs (wheat-specifically expressed effector genes) and WBEEs (wheat-barberry-commonly expressed effector genes) are in green and purple, while the others are in dark blue. DEGs abundant in barberry are in black. 
wheat and five were exclusively expressed in barberry. Since it was reported that the abundance of genes encoding cell walldegrading enzymes in the fungal genome were related to the composition of the host cell wall (O'Connell et al. 2012), we measured the contents of cellulose, hemicellulose, pectin, and lignin of wheat and barberry leaves to test if they are connected with the expression levels of the corresponding degradation genes (Fig. 7B). The results revealed a higher content of pectin in barberry leaves, which may be the reason for the extremely high transcriptional level of $P$. striiformis $\mathrm{f}$. sp. tritici pectinase genes during the infection of barberry. However, although with higher expression levels of $P$. striiformis f. sp. tritici cellulase and hemicellulase genes in the infected leaves of barberry, there was no significant difference in the content of cellulose and hemicellulose between the two hosts. In general, $P$. striiformis $\mathrm{f}$. sp. tritici uses different sets of carbohydrate-active enzymes (CAZymes), depending on the host.

\section{Expression profiles of nutrient transporters in wheat and barberry.}

As an obligate biotrophic pathogen, $P$. striiformis f. sp. tritici needs to uptake nutrients from living cells of its host through different kinds of transporters located in the haustorial membrane (Voegele et al. 2011). To dissect the mechanisms by $P$. striiformis f. sp. tritici nutrient acquisition from wheat and barberry, transcriptional profiles of genes involving hexose and amino-acid transporters were analyzed. Among the 35 hexose transporter genes identified in $P$. striiformis f. sp. tritici, most were expressed in both wheat and barberry (with a threshold of average TPM value $\geq 2.0$ for at least one timepoint) and exhibited no apparent difference in expression levels between the two hosts (Supplementary Fig. S3). However, three hexose transporter genes, PSTCY32_06236, PSTCY32_07224, and PSTCY32_13723, were preferentially expressed in wheat and one hexose transporter-encoding gene, PSTCY32_05623, was preferentially expressed in barberry (Supplementary Fig. S3). For the 25 amino-acid transporter genes identified in the $P$. striiformis f. sp. tritici genome, two ACT family members genes, PSTCY32_06701 and PSTCY32_00575, were found to be differentially expressed and abundant in barberry (Supplementary Fig. S4). However, an amino-acid transporter encoding gene from the LAT family, PSTCY32_26693, exhibited higher expression levels during the infection of wheat than that of barberry (Supplementary Fig. S4).

\section{DISCUSSION}

The in-depth transcriptomic profiling of $P$. striiformis $\mathrm{f}$. $\mathrm{sp}$. tritici presented in this study allows a comprehensive understanding of common and diverse mechanisms of $P$. striiformis f. sp. tritici pathogenesis on its two hosts. By constructing normalized cDNA libraries of $P$. striiformis $\mathrm{f}$. sp. tritici infected wheat and barberry leaves, we obtained sufficient sequencing depth $(43.0 \times$ to $62.7 \times)$ to compare these transcriptomes of $P$. striiformis f. sp. tritici during early stages of infection. The proportion of reads mapped to the $P$. striiformis $\mathrm{f}$. $\mathrm{sp}$. tritici reference genome ranged from 9.80 to $19.79 \%$. This is much higher than that in similar studies (Dobon et al. 2016). On this basis, genes expressed in one or both wheat and barberry during $P$. striiformis f. sp. tritici infection were identified by qualitative analysis. Overall, 18,328 genes were expressed in at least one sample, and more genes were detected in barberry than in wheat, suggesting that more genes or gene products are involved in barberry infection and a more complex interaction between $P$. striiformis f. sp. tritici and its aecial host barberry. This finding could at least partially be explained by the fact that $P$. striiformis f. sp. tritici sexual reproduction on barberry was more complicated than asexual multiplication on wheat.
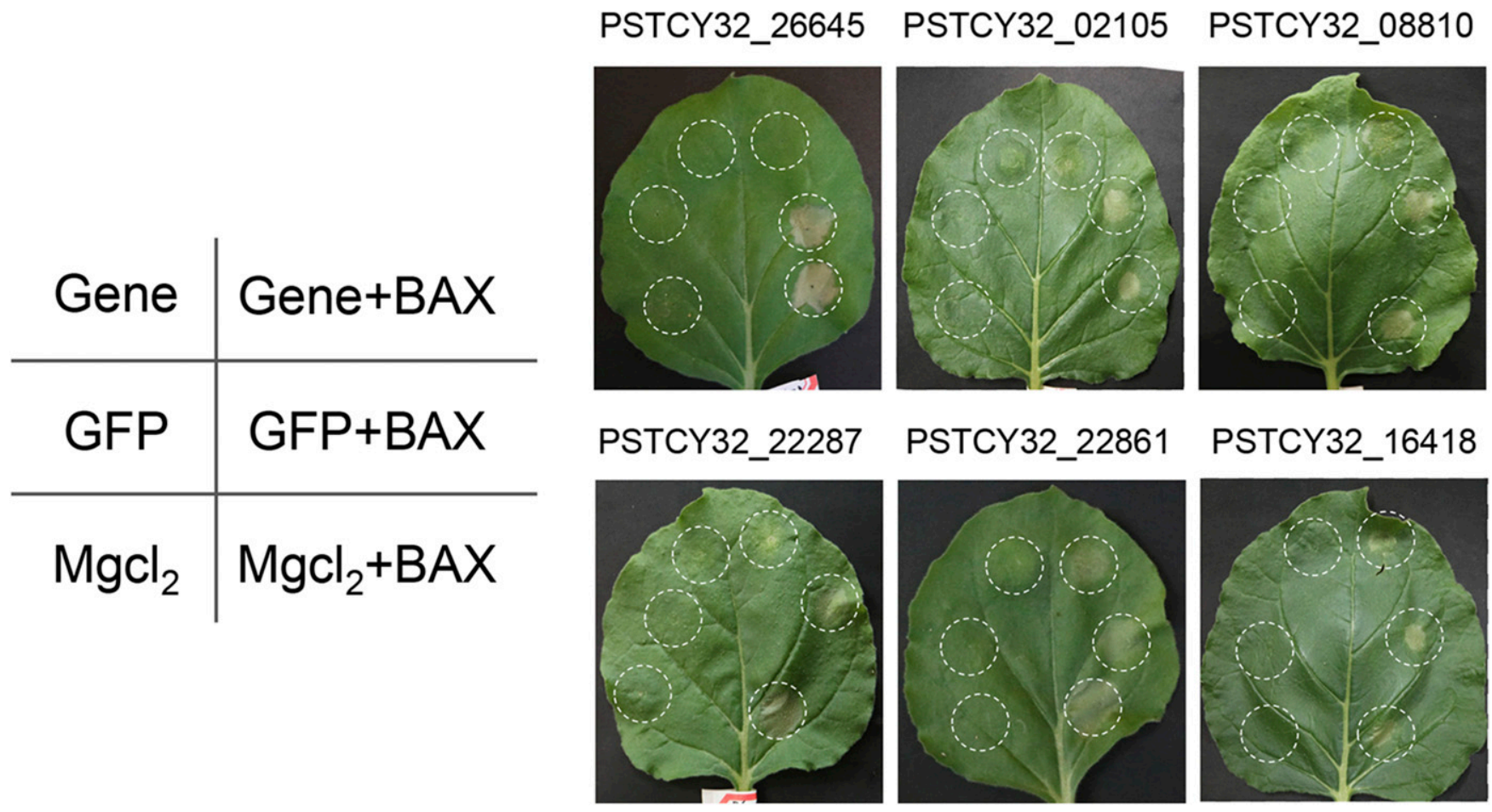

Fig. 6. Inhibition of BAX-induced cell death by Puccinia striiformis f. sp. tritici barberry-specifically expressed effector genes in tobacco. Nicotiana benthamiana leaves were infiltrated with buffer $\left(\mathrm{MgCl}_{2}\right)$, Agrobacterium tumefaciens cells containing a vector carrying $P$. striiformis f. sp. tritici candidate effector genes, and a negative control gene (eGFP); $24 \mathrm{~h}$ later, A. tumefaciens cells carrying BAX were infiltrated at the same position, according to the schematic diagram (left panel). The phenotypes were photographed at 5 days postinfiltration with BAX (right panel). 
The interactions of asexual urediniospores and telial host have been extensively studied (Dobon et al. 2016; Garnica et al. 2013; Schwessinger et al. 2018). However, little was known about the transcriptome of rust fungi at the sexual stage. Only a few transcriptomic studies have focused on basidiospores during the infection of its aecial host. Although at a limited scale, the transcriptome across all life cycle stages of Puccinia triticina was estimated and expression profiles of CSEPs in its two hosts, wheat and meadow rue (Thalictrum speciosissimum), were assessed (Cuomo et al. 2017). In another study, transcriptomes of Cronartium ribicola aeciospores, urediniospores, and two infection stages on the aecial host (western white pine) were compared, while no infection stage on the telial host (Ribes nigrum) was included (Liu et al. 2015). For M. laricipopulina, the causal agent of poplar rust, transcriptomic data for basidia, infected larch needles, urediniospores, and infected poplar leaves were compared (Lorrain et al. 2018). Overall, 1,436 and 1,531 genes were found to be specifically expressed at the sexual and the asexual stage, respectively. In the study reported here, timepoints representing haustoria and secondary hyphal formation (4 dpi of basidiospores on barberry and 2 dpi of urediniospores on wheat) were chosen to represent the early stage of $P$. striiformis $\mathrm{f}$. sp. tritici infection. The timepoint choice of the sampling provided comparable parallel datasets and allowed us to determine gene expression more precisely and identify host-specific expressed genes of significance for infection. Although a set of $P$. striiformis f. sp. tritici genes have been found to be host-specific, more genes were simultaneously detected during the two different host colonizations, despite the fact that these two plants are phylogenetically distant. This finding was consistent with the transcriptomic study on the infection of poplar and larch by $M$. larici-populina (Lorrain et al. 2018).

Effectors are key players for pathogenicity. The significant overrepresented CSEPs in WEGs or BEGs (18.3 and $12.0 \%$ versus overall CSEP proportion of $3.2 \%$ ) were observed. Similarly, a relatively high proportion of small secreted proteins was found to be enriched in highly expressed genes specific to poplar or larch. These results suggested that CSEPs may also contribute to host specificity. Actually, many research results have proven the roles of pathogen CSEPs in host specificity (Borah et al. 2018). For example, a recent study demonstrated that several effector proteins recognized by corresponding resistance genes in barley or related grass determine the host range of powdery mildew pathogen (Bourras et al. 2019).

In this study, a quantitative analysis was performed to allow us to compare the transcriptional levels of different sets of pathogenic genes during the infection of two hosts. In general, the transcription patterns in different hosts were consistent with the data obtained in qualitative analysis using normalized library. Additionally, no obvious difference was observed between the $P$. striiformis f. sp. tritici transcriptome at 1 and 2 dpi in wheat or between that at 3 and 4 dpi in barberry. However, some genes still exhibited clear transition in expression during the early infection, such as three WEEs (PSTCY32_00469,
A

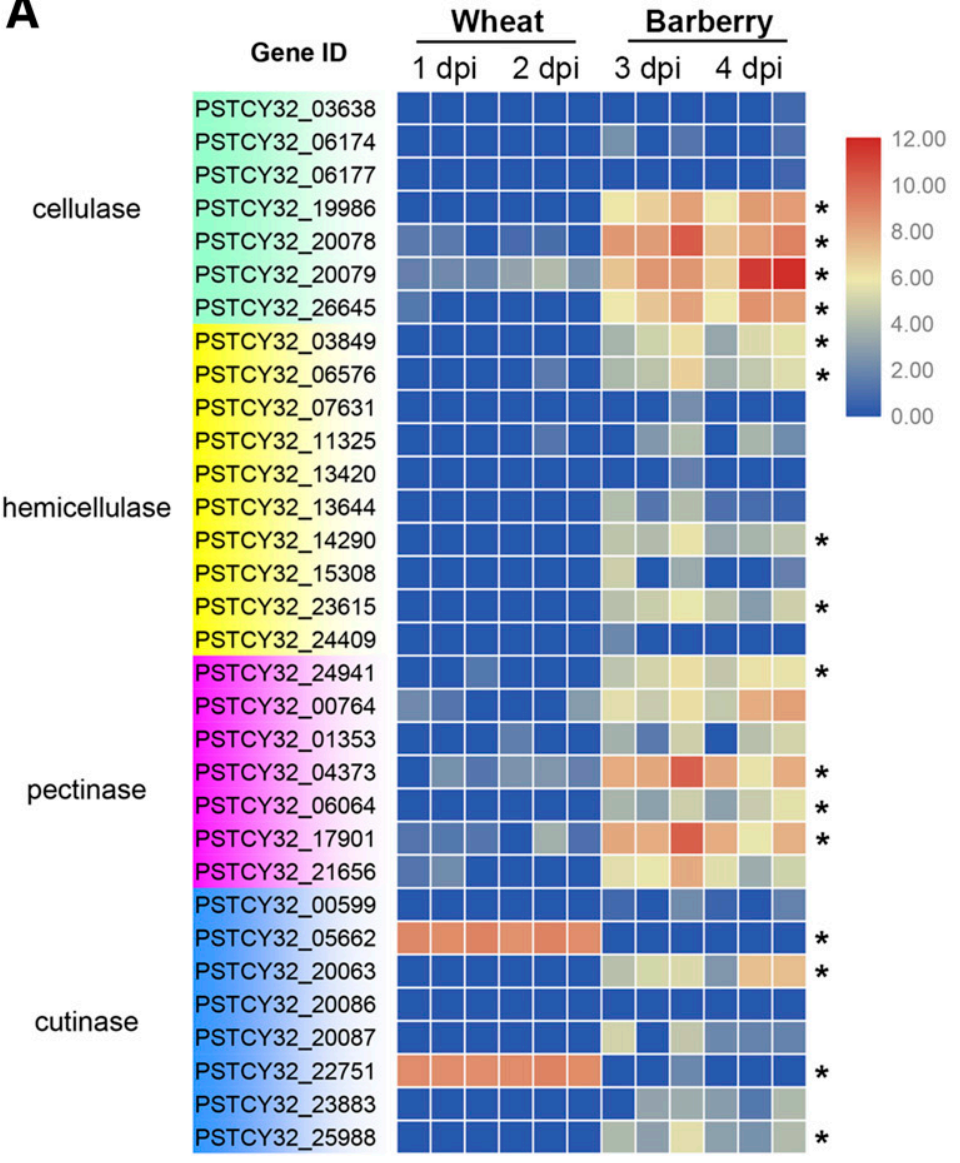

B

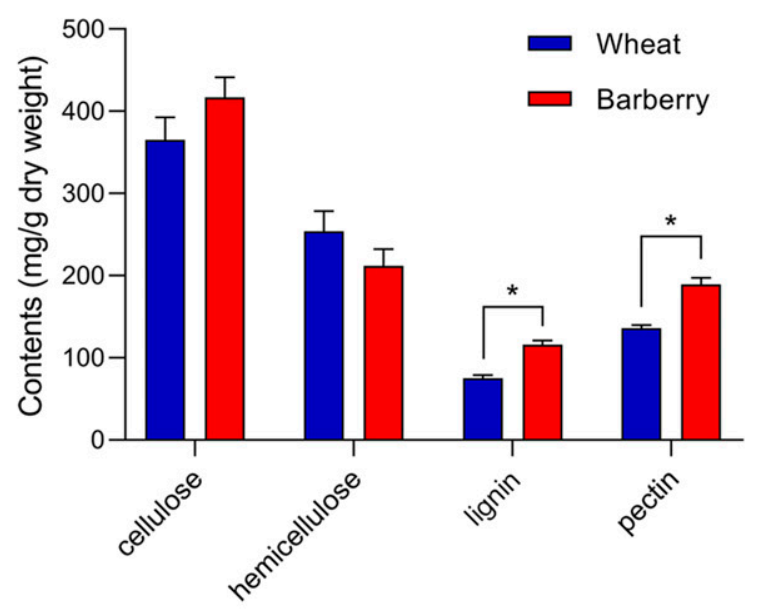

Fig. 7. Expression profiling of Puccinia striiformis f. sp. tritici secreted cell wall-degrading enzyme genes and contents of wheat and barberry cell-wall components. A, Expression levels (transcript per million values after the logarithm) of $P$. striiformis $\mathrm{f}$. sp. tritici cell wall-degrading enzyme genes at 1 and 2 days postinoculation (dpi) of wheat and 3 and 4 dpi of barberry. B, Concentration of cell-wall components of wheat and barberry leaves. Asterisks represent $P$. striiformis f. sp. tritici differentially expressed genes in wheat and barberry. 
PSTCY32_18558, and PSTCY32_20164) that have sharp increased expression levels from 1 to $2 \mathrm{dpi}$. These effector genes may play critical roles during the initial penetration of wheat by $P$. striiformis f. sp. tritici.

To successfully penetrate into plant tissue and cells, a rust fungus needs to secrete different sets of enzymes (glycohydrolase) to degrade the plant cuticle and cell wall. During the $P$. striiformis f. sp. tritici infection of barberry, most of the pectinase genes as well as cellulose and hemicellulose genes expressed with high levels, while no or very low levels were detected during the infection of wheat. This might be due to the higher content of pectin in barberry cell walls, but a more probable explanation would be the extra-thick outer wall of epidermal cells compared with the mesophyll cells (Amanda et al. 2016). In addition, unexpectedly, two cutinases were highly expressed in wheat while $P$. striiformis f. sp. tritici penetrated into wheat leaf tissue through stomata. A reasonable explanation should be that the wheat cuticle destroyed by cutinases may facilitate the adhesion of the urediniospores germ tubes on the leaf surface, as was found in broad bean rust (Deising et al. 1992; Schäfer 1993). The adhesion of germlings on epidermis of wheat leaves are of extra significance, since no appressoria were formed during the $P$. striiformis f. sp. tritici infection of wheat (Moldenhauer et al. 2006). Thus, $P$. striiformis f. sp. tritici uses different sets of CAZymes, depending not only on host cell-wall composition but also related to the host-tissue penetration mechanisms of basidiospores and urediniospores. Conversely, more common genes involved nutrient absorption were expressed both in wheat and in barberry, indicating that $P$. striiformis $\mathrm{f}$. sp. tritici uses a similar way to absorb nutrients from wheat and barberry.

A heteroecious grass rust requires two phylogenetically different hosts to complete their life cycle. Usually, they undergo sexual reproduction on one plant species and asexual propagation on another unrelated plant species. However, it has long been unclear that the biological significance of this lifestyle and the relationship of the two hosts. By the combination of phylogenetic and hologenetic analysis, Leppik et al. (1959) postulated that the aecial host of a cereal rust fungus, families Berberidaceae and Rhamnaceae or other arboreous families of primitive angiosperms, might be the primary host and graminaceous plants are the secondary host of a heteroecious grass rust fungus. Whether the telia or the aecial stage is more primitive and ancestral for a grass rust fungus remains considerably controversial, due to the lack of experimental evidence. In our study, over 300 effectors were specifically expressed in barberry, and a higher proportion of conserved genes were preferentially expressed in barberry than that in wheat. These results implied a long coevolutionary relationship between $P$. striiformis f. sp. tritici and barberry. As a matter of fact, Berberidaceae plants, belonging to primitive angiosperms and originating from 146 to 113 million years ago, are evolutionarily older than grasses (Poaceae originates from 65 to 110 million years ago) (Angiosperm Phylogeny website), which makes them interact with rust fungi earlier according to the coevolutionary relationship between a rust fungus and its host (Aime et al. 2018). Furthermore, besides P. striiformis, Berberis spp. are aecial hosts of a wide range of grass rust fungi, including at least seven Puccinia spp. (e.g., P. graminis, $P$. striiformis, $P$. montanensis, $P$. brachypodii, $P$. pigmea, $P$. koeleriae, and $P$. arrhenatheri) (Bartaula et al. 2019; Huang et al. 2019). If barberry as the primary host for $P$. striiformis $\mathrm{f}$. sp. tritici is accepted, it will raise the question of how the ancestor of barberry rust fungi completed its life cycle, since the aeciospores produced on barberry could not come back (Jiao et al. 2017). One possibility would be that the ancestor of a barberry rust fungus had a more ancient telial host than Berberidaceae, such as Cupressacea. Another possibility is that the ancient rust fungi spent all their lives on barberry-like Cumminsiella mirabilissima, which produces all five types of spores on mahonia, a kind of Berberidaceae plant that is closely related to barberry and can serve as the aecial host of $P$. striiformis f. sp. tritici (Ruske and Dörfelt 2010; Wang and Chen 2013). Several studies have reported that uredia and telia of $P$. graminis $\mathrm{f} . \mathrm{sp}$. tritici can be produced on barberry under natural and laboratory conditions (Critopoulos 1947; Newton and Johnson 1937). Thus, the ancestor of barberry rust fungi may have adapted themselves to the emerging grasses in the neighborhood and switched the telial stage to them. Altogether, the analysis of orthologous genes for host-specific expressed genes in this study offers a new perspective for origin and evolution study of rust fungi.

So far, numerous $P$. striiformis f. sp. tritici effectors have been identified and their pathogenic roles in the pathogenwheat interaction have been extensively revealed (Cheng et al. 2015, 2017; Qi et al. 2019a; Xu et al. 2019; Yang et al. 2020; Zhao et al. 2018). With the knowledge of preferential or specific expression in wheat or barberry, we identified six BEEs that were capable of suppressing BAX-induced cell death in tobacco. Future functional characterization of these genes may help to develop resistance barberry materials by host-induced gene silencing strategies (Qi et al. 2019b). In addition, those candidate effectors expressed in both hosts may represent "core effectors" that are conserved among rust fungi and play key roles in the rust basic pathogenicity. More attention should be given to the in-depth study of these core effectors to discover the molecular basis for rust pathogenicity.

\section{MATERIALS AND METHODS}

\section{Plant materials and inoculation.}

Seedlings of the $P$. striiformis $\mathrm{f}$. sp. tritici-susceptible wheat cultivar MX169 were grown in the greenhouse at $16^{\circ} \mathrm{C}$ and a 16-h light and 8-h dark cycle. Ten-day-old seedlings were inoculated with fresh urediniospores of $P$. striiformis f. sp. tritici strains CYR32 and V26 and were incubated for $24 \mathrm{~h}$ in $100 \%$ humidity at $9^{\circ} \mathrm{C}$ in the dark. Barberry (Berberis shensiana) plants were grown in under $70 \%$ relative humidity at $16^{\circ} \mathrm{C}$ and 16-h light and 8-h dark cycle. Three- to four-month-old barberry seedlings were inoculated with CYR32 and V26 basidiospores produced from germinating teliospores according to the method described by Zhao et al. (2013a).

\section{Histological treatment and observation.}

The wheat leaf segments and barberry leaf discs infected by $P$. striiformis f. sp. tritici were fixed and decolorized in decolorizing solution (ethyl alcohol and acetic acid, 1:1 vol/vol), followed by immersion overnight in chloral hydrate. The decolorized samples were then autoclaved in $1.5 \mathrm{ml}$ of $1 \mathrm{M} \mathrm{KOH}$ at $121^{\circ} \mathrm{C}$ for 5 to $6 \mathrm{~min}$. Those samples were washed three times with $50 \mathrm{mM}$ Tris- $\mathrm{HCl}(\mathrm{pH} \mathrm{7.4)}$ ) for $15 \mathrm{~min}$ and were stained with a $20 \mu \mathrm{g} / \mathrm{ml}$ solution of wheat germ agglutinin conjugated to Alexa-488 (Thermo Fisher Scientific). The fluorescentstained samples were observed under blue light excitation (excitation wavelength 450 to $480 \mathrm{~nm}$, emission wavelength $515 \mathrm{~nm}$ ) using an Olympus BX-53 microscope (ocular: 10×, objective: 20x) and CellSens Entry software (version V1.7). Penetration frequencies for $P$. striiformis f. sp. tritici urediniospores on wheat leaves represent the percentage of germinated spores penetrating the mesophyll cells and forming haustoria. Penetration frequencies for P. striiformis f. sp. tritici basidiospores on barberry leaves represent the percentage of germinated spores penetrating into epidermal cells and forming OIVs. 
RNA extraction, library preparation, and sequencing.

Entire leaf tissue was taken from barberry plants at 3 and 4 dpi and from wheat plants at 1 and 2 dpi and were then immediately frozen in liquid nitrogen. Frozen leaf samples were then ground in liquid nitrogen, and total RNA was isolated using the Qiagen (Doncaster, Australia) Plant RNeasy kit, following manufacturer instructions. RNA was checked for integrity on an Agilent 2100 Bioanalyzer. First-strand cDNA was synthesized using random hexamer primer and M-MuLV reverse transcription. Normalized and nonnormalized cDNA libraries were generated for qualitative and quantitative analyses of $P$. striiformis $\mathrm{f}$. sp. tritici transcriptome. For qualitative analysis, normalized cDNA libraries were constructed using the DSN (duplex-specific nuclease)-normalization technology with a high gene-discovery rate (Bogdanova et al. 2008). Briefly, after denaturation of double-stranded (ds) cDNA flanked with adapters, it was subjected to renature at $68^{\circ} \mathrm{C}$ and was treated with DSN (Evrogen; Moscow). During renaturation, abundant transcripts are converted to the ds form more effectively than those that are less frequent. Thus, two fractions are formed, specifically, a ds fraction of abundant cDNA and a normalized single-stranded cDNA. The ds cDNA fraction is then degraded by DSN. After that, the undigested fragments were then amplified by long-distance polymerase chain reaction (PCR). The products were then random fragmented and adapters for Illumina sequencing were ligated. Finally, the resulting tagged cDNA libraries were used for 150-bp paired-ends sequencing on the Illumina Hi-Seq 2000 Platform (Illumina, San Diego, CA, U.S.A.). For quantitative analysis, nonnormalized cDNA libraries were constructed following manufacturer instructions for the K02421-TS RNA transcriptome discovery kit (Gnomegen, San Diego, CA, U.S.A.). Amplified cDNA fragments were then used for 150-bp paired-ends sequencing on the Illumina Hi-Seq 2000 Platform.

\section{Gene expression analysis and orthologous gene identification.}

Raw reads were processed to trim adapter sequences and remove low-quality sequences with Q20 filtering, using Trimmomatic v0.32 (Bolger et al. 2014) with default settings, and were then evaluated by Fastqc v0.10.0 (Andrews 2010). After adapter trimming and quality trimming, the clean reads were mapped to the updated reference genome of $P$. striiformis $\mathrm{f}$. sp. tritici CYR32 (Zheng et al. 2013), using TopHat2 (v2.1.0) with Bowtie2 (Kim et al. 2013). Novel transcripts were identified using Cufflinks (version 2.2.1) in "reference annotation based transcript assembly" mode with sequence bias correction enabled. Then, the transcript abundances (inferred in TPM) were calculated by Samtools (Li et al. 2009).

Expression levels from normalized samples were used to characterize host-specific expressed genes. $P$. striiformis f. sp. tritici genes with TPM values above 2.0 in wheat and below 2.0 in barberry and the ratio between the two hosts above 5.0 for both $P$. striiformis f. sp. tritici isolates were defined as WEGs. Likewise, genes with TPM values above 2.0 in barley and below 2.0 in wheat and the ratio between the two hosts above 5.0 for both $P$. striiformis f. sp. tritici isolates were defined as BEGs. Genes with TPM values above 2.0 in both hosts were designated as WBEGs. For orthologous gene identification, the protein sequence of each host-specifically expressed gene was used as query to search against each other Basidiomycete genome data using BLASTP with an Evalue below $10^{-3}$.

Differential expression analyses were performed for $P$. striiformis f. sp. tritici genes with the edgeR R/Bioconductor package (Robinson et al. 2010). The read counts were first normalized using the TMM (trimmed mean of $M$ values) method of edgeR and, then, the logarithm of the counts per million to the base 2 were used for further statistical analysis using the Limma R/Bioconductor package. DEGs were identified based on a fold change $\geq 2$ and a false discovery rate $\leq 0.05$ between samples.

\section{Identification of effector genes, cell wall-degradation genes and transporter genes.}

CSEPs were predicted using bioinformatics software according to their biological characteristics. Briefly, P. striiformis f. sp. tritici secreted proteins carrying a signal peptide were identified by SignalP 4.0 (Petersen et al. 2011) with a D-cutoff value of 0.34 . Then transmembrane proteins (contain at least one transmembrane domain after the first 60 amino acids or at least two transmembrane domains in total) were predicted by TMHMM 2.0 (Krogh et al. 2001) and were excluded from the $P$. striiformis f. sp. tritici secretome. Finally, CSEPs were predicted by EffectorP v2.0 (Sperschneider et al. 2018).

To identify cell wall-degradation proteins, $P$. striiformis $\mathrm{f}$. $\mathrm{sp}$. tritici protein sequences were subjected to a dbCAN2 meta server search to identify secreted CAZymes by HMMER program (available online on the dbCAN server) (Zhang et al. 2018). Proteins annotated as GH6, GH7, GH12, GH45, GH61, GH74, and GH94 were attributed to the cellulases. Similarly, CE1, GH10, GH11, GH26, GH29, GH43, GH51, GH53, GH54, GH62, GH67, and GH93 belong to the hemicellulases. CE8, PL1, PL2, PL3, PL4, PL9, PL10, GH28, GH78, and GH88 belong to the pectinases. While proteins annotated as CE5 CAZymes belong to cutinase (Zhao et al. 2013b).

To identify $P$. striiformis f. sp. tritici hexose transporters, the protein sequences of yeast (Saccharomyces cerevisiae) hexose transporters HXT1 to HXT7 (Luyten et al. 2002) were used as queries to search against the CYR32 genome, using the tBLASTn program. Finally, 35 P. striiformis f. sp. tritici hexose transporter genes with $P$ values less than $10 \mathrm{e}-3$ were identified. Likewise, using amino-acid transporter proteins reported, in a previous article, as seed sequences (Struck 2015), we identified 25 amino-acid transporter genes in the CYR32 genome.

The cluster analysis heat map for effector genes, cell walldegradation genes and transporter genes was drawn using TBtools (Chen et al. 2020).

\section{GO and KEGG analysis of $P$. striiformis f. sp. tritici DEGs during infection of wheat and barberry.}

GO annotation was performed by searching 29,544 $P$. striiformis f. sp. tritici protein sequences against four databases including Pfam, PANTHER, CDD, and COIL using Interproscan v5.39-77.0 (Jones et al. 2014). KEGG annotation was performed by online KAAS tools. Then, the $\mathrm{R}$ package of clusterProfiler were used for enrichment analysis (Yu et al. 2012).

\section{Quantitative determination of cell-wall composition.}

Wheat and barberry leaf samples at the two-week and sixmonth stages, respectively, were collected and dried to a constant weight at $50^{\circ} \mathrm{C}$. Then, the dried leaf samples $(0.1 \mathrm{~g})$ were ground into fine powders, and the cell-wall materials (CWM) were extracted by removing the alcohol-soluble components and starch, using ethanol/acetone extraction and $\alpha$-amylase digestion according to the method described by Pettolino et al. (2012).

Total cellulose contents of the cell wall from wheat and barberry leaf samples were measured using the colorimetric Anthrone assay, according to the method previously reported (Foster et al. 2010b; Updegraff 1969). Briefly, the obtained 
CWM was firstly hydrolyzed by $2 \mathrm{M}$ trifluoroacetic acid. After centrifugation, the precipitate and supernatant were used for cellulose and hemicellulose analyses, respectively. For cellulose measurement, the precipitate was incubated with $1 \mathrm{ml}$ of Updegraff reagent (acetic acid, citric acid, and water, 8:1:2 $\mathrm{vol} / \mathrm{vol} / / \mathrm{vol}$ ) at $100^{\circ} \mathrm{C}$ for $1 \mathrm{~h}$ and was pretreated with $72 \%$ sulfuric acid for Saeman hydrolysis. For hemicellulose measurement, the supernatant was directly treated with $72 \%$ sulfuric acid. Then, the released glucose was reacted with $0.2 \%$ Anthrone reagent at $100^{\circ} \mathrm{C}$ for $10 \mathrm{~min}$, and the resulting blue reaction products were measured at $620 \mathrm{~nm}$ wavelength. The contents of cellulose and hemicellulose were presented as equivalents of glucose used in the standard curve.

Total pectin was extracted from CWM with ammonium oxalate, and pectin contents were determined according to the colorimetric method at wavelength of $520 \mathrm{~nm}$, as described by Blumenkrantz and Asboe-Hansen (1973). The contents of pectin were presented as equivalents of galacturonic acid used as the standard.

The lignin content of the leaf samples was determined using the acetyl bromide method as previously reported (Foster et al. 2010a; Hatfield et al. 1999). Lignin was quantified with the acetyl bromide method using absorbance values at $280 \mathrm{~nm}$. An extinction coefficient of 17.75 was used to calculate the lignin content of all samples.

All the absorbance measurements were performed by a Synergy H1 hybrid multi-mode microplate reader (BioTek Instrumnets, Winooski, VT, U.S.A.). Four biological replicates were performed for each experiment. $T$-tests were used to assess statistical significance.

\section{Agrobacterium tumefaciens infiltration assays.}

To screen $P$. striiformis $\mathrm{f}$. sp. tritici candidate effectors that can suppress Bax-induced cell death in N. benthamiana, we infiltrated A. tumefaciens cells containing pGR107-PVX constructs expressing candidate effector genes or $\beta$-glucuronidase genes (as a control) into leaves, followed $24 \mathrm{~h}$ later by inoculation at the same site with A. tumefaciens cells carrying pGR107-PVX-Bax. Symptoms were observed and recorded at 5 dpi.

\section{ACKNOWLEDGMENTS}

We are grateful to the review of this manuscript by R. T. Vögele, Institute for Phytomedicine, University of Hohenheim, Germany.

\section{AUTHOR-RECOMMENDED INTERNET RESOURCES}

Angiosperm Phylogeny website:

https://www.mobot.org/MOBOT/research/APweb

dbCAN2 meta server: http://bcb.unl.edu/dbCAN2/index.php

KAAS tools: https://www.genome.jp/kaas-bin/kaas_main

\section{LITERATURE CITED}

Aime, M. C., Bell, C. D., and Wilson, A. W. 2018. Deconstructing the evolutionary complexity between rust fungi (Pucciniales) and their plant hosts. Stud. Mycol. 89:143-152.

Aime, M. C., McTaggart, A. R., Mondo, S. J., and Duplessis, S. 2017. Phylogenetics and phylogenomics of rust fungi. Pages 267-307 in: Fungal Phylogenetics and Phylogenomics. Academic Press, New York.

Amanda, D., Doblin, M. S., Galletti, R., Bacic, A., Ingram, G. C., and Johnson, K. L. 2016. DEFECTIVE KERNEL1 (DEK1) regulates cell walls in the leaf epidermis. Plant Physiol. 172:2204-2218.

Andrews, S. 2010. FastQC: A quality control tool for high throughput sequence data. Babraham Bioinformatics, Cambridge. Published online. http://www.bioinformatics.babraham.ac.uk/projects/fastqc

Bartaula, R., Melo, A. T. O., Kingan, S., Jin, Y., and Hale, I. 2019. Mapping non-host resistance to the stem rust pathogen in an interspecific barberry hybrid. BMC Plant Biol. 19:319.
Blumenkrantz, N., and Asboe-Hansen, G. 1973. New method for quantitative determination of uronic acids. Anal. Biochem. 54:484-489.

Bogdanova, E. A., Shagin, D. A., and Lukyanov, S. A. 2008. Normalization of full-length enriched cDNA. Mol. Biosyst. 4:205-212.

Bolger, A., Lohse, M., and Usadel, B. 2014. Trimmomatic: A flexible trimmer for Illumina sequence data. Bioinformatics 30:2114-2120.

Borah, N., Albarouki, E., and Schirawski, J. 2018. Comparative methods for molecular determination of host-specificity factors in plantpathogenic fungi. Int. J. Mol. Sci. 19:863.

Bourras, S., Kunz, L., Xue, M., Praz, C. R., Müller, M. C., Kälin, C., Schläfli, M., Ackermann, P., Flückiger, S., Parlange, F., Menardo, F., Schaefer, L. K., Ben-David, R., Roffler, S., Oberhaensli, S., Widrig, V., Lindner, S., Isaksson, J., Wicker, T., Yu, D., and Keller, B. 2019. The AvrPm3-Pm3 effector-NLR interactions control both race-specific resistance and host-specificity of cereal mildews on wheat. Nat. Commun. 10:2292.

Cantu, D., Segovia, V., MacLean, D., Bayles, R., Chen, X., Kamoun, S., Dubcovsky, J., Saunders, D. G. O., and Uauy, C. 2013. Genome analyses of the wheat yellow (stripe) rust pathogen Puccinia striiformis f. $\mathrm{sp}$ tritici reveal polymorphic and haustorial expressed secreted proteins as candidate effectors. BMC Genomics 14:270.

Chen, C., Chen, H., Zhang, Y., Thomas, H. R., Frank, M. H., He, Y., and Xia, R. 2020. TBtools: An integrative toolkit developed for interactive analyses of big biological data. Mol. Plant 13:1194-1202.

Chen, X., Coram, T., Huang, X., Wang, M., and Dolezal, A. 2013. Understanding molecular mechanisms of durable and non-durable resistance to stripe rust in wheat using a transcriptomics approach. Curr. Genomics 14:111-126.

Cheng, Y., Wang, X., Yao, J., Voegele, R. T., Zhang, Y., Wang, W., Huang, L., and Kang, Z. 2015. Characterization of protein kinase PsSRPKL, a novel pathogenicity factor in the wheat stripe rust fungus. Environ. Microbiol. 17:2601-2617.

Cheng, Y., Wu, K., Yao, J., Li, S., Wang, X., Huang, L., and Kang, Z. 2017. PSTha5a23, a candidate effector from the obligate biotrophic pathogen Puccinia striiformis f. sp. tritici, is involved in plant defense suppression and rust pathogenicity. Environ. Microbiol. 19:1717-1729.

Critopoulos, P. D. 1947. Production of teliospores and uredospores of Puccinia graminis on Berberis cretica in nature. Mycologia 39:145-151.

Cuomo, C. A., Bakkeren, G., Khalil, H. B., Panwar, V., Joly, D., Linning, R., Sakthikumar, S., Song, X., Adiconis, X., Fan, L., Goldberg, J. M., Levin, J. Z., Young, S., Zeng, Q., Anikster, Y., Bruce, M., Wang, M., Yin, C., McCallum, B., Szabo, L. J., Hulbert, S., Chen, X., and Fellers, J. P. 2017. Comparative analysis highlights variable genome content of wheat rusts and divergence of the mating loci. G3 Genes Genom. Genet. 7 : 361-376.

Deising, H., Nicholson, R. L., Haug, M., Howard, R. J., and Mendgen, K. 1992. Adhesion pad formation and the involvement of cutinase and esterases in the attachment of uredospores to the host cuticle. Plant Cell 4:1101-1111.

Dobon, A., Bunting, D. C. E., Cabrera-Quio, L. E., Uauy, C., and Saunders, D. G. O. 2016. The host-pathogen interaction between wheat and yellow rust induces temporally coordinated waves of gene expression. BMC Genomics 17:380.

Foster, C. E., Martin, T. M., and Pauly, M. 2010a. Comprehensive compositional analysis of plant cell walls (lignocellulosic biomass) part I: Lignin. J. Vis. Exp. 37:1745.

Foster, C. E., Martin, T. M., and Pauly, M. 2010b. Comprehensive compositional analysis of plant cell walls (lignocellulosic biomass) part II: Carbohydrates. J. Vis. Exp. 37:1837.

Garnica, D. P., Upadhyaya, N. M., Dodds, P. N., and Rathjen, J. P. 2013. Strategies for wheat stripe rust pathogenicity identified by transcriptome sequencing. PLoS One 8:e67150.

Hatfield, R. D., Grabber, J., Ralph, J., and Brei, K. 1999. Using the acetyl bromide assay to determine lignin concentrations in herbaceous plants: Some cautionary notes. J. Agric. Food Chem. 47:628-632.

Huang, S., Zuo, S., Zheng, D., Liu, Y., Du, Z., Kang, Z., and Zhao, J. 2019. Three formae speciales of Puccinia striiformis were identified as heteroecious rusts based on completion of sexual cycle on Berberis spp. under artificial inoculation. Phytopathol. Res. 1:14.

Jiao, M., Tan, C., Wang, L., Guo, J., Zhang, H., Kang, Z., and Guo, J. 2017. Basidiospores of Puccinia strifformis f. sp. tritici succeed to infect barberry, while urediniospores are blocked by non-host resistance. Protoplasma 254:2237-2246.

Jones, P., Binns, D., Chang, H. Y., Fraser, M., Li, W., McAnulla, C., McWilliam, H., Maslen, J., Mitchell, A., Nuka, G., Pesseat, S., Quinn, A. F., Sangrador-Vegas, A., Scheremetjew, M., Yong, S. Y., Lopez, R., and Hunter, S. 2014. InterProScan 5: Genome-scale protein function classification. Bioinformatics 30:1236-1240. 
Kim, D., Pertea, G., Trapnell, C., Pimentel, H., Kelley, R., and Salzberg, S. L. 2013. TopHat2: Accurate alignment of transcriptomes in the presence of insertions, deletions and gene fusions. Genome Biol. 14: R36.

Krogh, A., Larsson, B., von Heijne, G., and Sonnhammer, E. L. L. 2001. Predicting transmembrane protein topology with a hidden Markov model: Application to complete genomes. J. Mol. Biol. 305:567-580.

Leppik, E. E. 1959. Some viewpoints on the phylogeny of rust fungi. III. Origin of grass rusts. Mycologia 51:512-528.

Li, H., Handsaker, B., Wysoker, A., Fennell, T., Ruan, J., Homer, N., Marth, G., Abecasis, G., and Durbin, R. 2009. The sequence alignment/map format and SAMtools. Bioinformatics 25:2078-2079.

Liu, J., Guan, T., Zheng, P., Chen, L., Yang, Y., Huai, B., Li, D., Chang, Q., Huang, L., and Kang, Z. 2016. An extracellular Zn-only superoxide dismutase from Puccinia striiformis confers enhanced resistance to hostderived oxidative stress. Environ. Microbiol. 18:4118-4135.

Liu, J. J., Sturrock, R. N., Sniezko, R. A., Williams, H., Benton, R., and Zamany, A. 2015. Transcriptome analysis of the white pine blister rust pathogen Cronartium ribicola: De novo assembly, expression profiling, and identification of candidate effectors. BMC Genomics 16:678.

Lorrain, C., Marchal, C., Hacquard, S., Delaruelle, C., Pétrowski, J., Petre, B., Hecker, A., Frey, P., and Duplessis, S. 2018. The rust fungus Melampsora larici-populina expresses a conserved genetic program and distinct sets of secreted protein genes during infection of its two host plants, larch and poplar. Mol. Plant-Microbe Interact 31:695-706.

Luyten, K., Riou, C., and Blondin, B. 2002. The hexose transporters of Saccharomyces cerevisiae play different roles during enological fermentation. Yeast 19:713-726.

Moldenhauer, J., Moerschbacher, B. M., and Van der Westhuizen, A. J. 2006. Histological investigation of stripe rust (Puccinia striiformis $\mathrm{f}$. $\mathrm{sp}$ tritici) development in resistant and susceptible wheat cultivars. Plant Pathol. 55:469-474

Newton, M., and Johnson, T. 1937. Production of uredia and yelia of Puccinia graminis on Berberis vulgaris. Nature 139:800-801.

O'Connell, R. J., Thon, M. R., Hacquard, S., Amyotte, S. G., Kleemann, J., Torres, M. F., Damm, U., Buiate, E. A., Epstein, L., Alkan, N., Altmüller, J., Alvarado-Balderrama, L., Bauser, C. A., Becker, C., Birren, B. W., Chen, Z., Choi, J., Crouch, J. A., Duvick, J. P., Farman, M. A., Gan, P., Heiman, D., Henrissat, B., Howard, R. J., Kabbage, M., Koch, C., Kracher, B., Kubo, Y., Law, A. D., Lebrun, M. H., Lee, Y. H., Miyara, I., Moore, N., Neumann, U., Nordström, K., Panaccione, D. G., Panstruga, R., Place, M., Proctor, R. H., Prusky, D., Rech, G., Reinhardt, R., Rollins, J. A., Rounsley, S., Schardl, C. L., Schwartz, D. C., Shenoy, N., Shirasu, K., Sikhakolli, U. R., Stüber, K., Sukno, S. A., Sweigard, J. A., Takano, Y., Takahara, H., Trail, F., van der Does, H. C., Voll, L. M., Will, I., Young, S., Zeng, Q., Zhang, J., Zhou, S., Dickman, M. B., SchulzeLefert, P., Ver Loren van Themaat, E., Ma, L. J., and Vaillancourt, L. J. 2012. Lifestyle transitions in plant pathogenic Colletotrichum fungi deciphered by genome and transcriptome analyses. Nat. Genet. 44: 1060-1065.

Petersen, T. N., Brunak, S., von Heijne, G., and Nielsen, H. 2011. SignalP 4.0: Discriminating signal peptides from transmembrane regions. Nat. Methods 8:785-786.

Pettolino, F. A., Walsh, C., Fincher, G. B., and Bacic, A. 2012. Determining the polysaccharide composition of plant cell walls. Nat. Protoc. 7: 1590-1607.

Qi, T., Guo, J., Liu, P., He, F., Wan, C., Islam, M. A., Tyler, B. M., Kang, Z., and Guo, J. 2019a. Stripe rust effector PstGSRE1 disrupts nuclear localization of ROS-promoting transcription factor TaLOL2 to defeat ROS-induced defense in wheat. Mol. Plant 12:1624-1638.

Qi, T., Guo, J., Peng, H., Liu, P., Kang, Z., and Guo, J. 2019b. Host-induced gene silencing: A powerful strategy to control diseases of wheat and barley. Int. J. Mol. Sci. 20:206.

Roberts, A., Pimentel, H., Trapnell, C., and Pachter, L. 2011. Identification of novel transcripts in annotated genomes using RNA-Seq. Bioinformatics 27:2325-2329.

Robinson, M. D., McCarthy, D. J., and Smyth, G. K. 2010. edgeR: A Bioconductor package for differential expression analysis of digital gene expression data. Bioinformatics 26:139-140.

Ruske, E., and Dörfelt, H. 2010. Studies on the life history of the mahonia rust (Cumminsiella mirabilissima). Boletus 32:78-88.

Rutter, W. B., Salcedo, A., Akhunova, A., He, F., Wang, S., Liang, H., Bowden, R. L., and Akhunov, E. 2017. Divergent and convergent modes of interaction between wheat and Puccinia graminis f. sp. tritici isolates revealed by the comparative gene co-expression network and genome analyses. BMC Genomics 18:291.

Schäfer, W. 1993. The role of cutinase in fungal pathogenicity. Trends Microbiol. 1:69-71.

Schwessinger, B., Sperschneider, J., Cuddy, W. S., Garnica, D. P., Miller, M. E., Taylor, J. M., Dodds, P. N., Figueroa, M., Park, R. F., and Rathjen, J. P. 2018. A near-complete haplotype-phased genome of the dikaryotic wheat stripe rust fungus Puccinia striiformis f. $\mathrm{sp}$ tritici reveals high interhaplotype diversity. MBio 9:e02275-17.

Sperschneider, J., Dodds, P. N., Gardiner, D. M., Singh, K. B., and Taylor, J. M. 2018. Improved prediction of fungal effector proteins from secretomes with EffectorP 2.0. Mol. Plant Pathol. 19:2094-2110.

Struck, C. 2015. Amino acid uptake in rust fungi. Front. Plant Sci. 6:40.

Trapnell, C., Roberts, A., Goff, L., Pertea, G., Kim, D., Kelley, D. R., Pimentel, H., Salzberg, S. L., Rinn, J. L., and Pachter, L. 2012. Differential gene and transcript expression analysis of RNA-seq experiments with TopHat and Cufflinks. Nat. Protoc. 7:562-578.

Upadhyaya, N. M., Garnica, D. P., Karaoglu, H., Sperschneider, J., Nemri, A., Xu, B., Mago, R., Cuomo, C. A., Rathjen, J. P., Park, R. F., Ellis, J. G., and Dodds, P. N. 2015. Comparative genomics of Australian isolates of the wheat stem rust pathogen Puccinia graminis f. sp. tritici reveals extensive polymorphism in candidate effector genes. Front. Plant Sci. 5:759.

Updegraff, D. M. 1969. Semimicro determination of cellulose in biological materials. Anal. Biochem. 32:420-424.

Voegele, R. T., and Mendgen, K. W. 2011. Nutrient uptake in rust fungi: How sweet is parasitic life? Euphytica 179:41-55

Wang, B., Sun, Y., Song, N., Zhao, M., Liu, R., Feng, H., Wang, X., and Kang, Z. 2017. Puccinia striiformis f. sp. tritici microRNA-like RNA 1 (Pst-milR1), an important pathogenicity factor of Pst, impairs wheat resistance to $P$ st by suppressing the wheat pathogenesis-related 2 gene. New Phytol. 215:338-350.

Wang, M. N., and Chen, X. M. 2013. First report of Oregon grape (Mahonia aquifolium) as an alternate host for the wheat stripe rust pathogen (Puccinia striiformis f. sp tritici) under artificial inoculation. Plant Dis. 97:839.

Xu, Q., Tang, C., Wang, X., Sun, S., Zhao, J., Kang, Z., and Wang, X. 2019. An effector protein of the wheat stripe rust fungus targets chloroplasts and suppresses chloroplast function. Nat. Commun. 10:5571.

Yadav, I. S., Sharma, A., Kaur, S., Nahar, N., Bhardwaj, S. C., Sharma, T. R., and Chhuneja, P. 2016. Comparative temporal transcriptome profiling of wheat near isogenic line carrying Lr57 under compatible and incompatible interactions. Front. Plant Sci. 7:1943.

Yang, Q., Huai, B., Lu, Y., Cai, K., Guo, J., Zhu, X., Kang, Z., and Guo, J. 2020. A stripe rust effector Pst18363 targets and stabilises TaNUDX23 that promotes stripe rust disease. New Phytol. 225:880-895.

Yu, G., Wang, L. G., Han, Y., and He, Q. Y. 2012. clusterProfiler: An R package for comparing biological themes among gene clusters. OMICS 16:284-287.

Zhang, H., Yohe, T., Huang, L., Entwistle, S., Wu, P., Yang, Z., Busk, P. K., $\mathrm{Xu}$, Y., and Yin, Y. 2018. dbCAN2: A meta server for automated carbohydrate-active enzyme annotation. Nucleic Acids Res. 46 (W1) W95-W101.

Zhao, J., Wang, L., Wang, Z., Chen, X., Zhang, H., Yao, J., Zhan, G., Chen, W., Huang, L., and Kang, Z. 2013a. Identification of eighteen Berberis species as alternate hosts of Puccinia striiformis f. sp. tritici and virulence variation in the pathogen isolates from natural infection of barberry plants in China. Phytopathology 103:927-934.

Zhao, J., Wang, M., Chen, X., and Kang, Z. 2016. Role of alternate hosts in epidemiology and pathogen variation of cereal rusts. Annu. Rev. Phytopathol. 54:207-228.

Zhao, M., Wang, J., Ji, S., Chen, Z., Xu, J., Tang, C., Chen, S., Kang, Z., and Wang, X. 2018. Candidate effector Pst_8713 impairs the plant immunity and contributes to virulence of Puccinia striiformis f. sp tritici. Front. Plant Sci. 9:1294.

Zhao, Z., Liu, H., Wang, C., and Xu, J. R. 2013b. Comparative analysis of fungal genomes reveals different plant cell wall degrading capacity in fungi. BMC Genomics 14:274.

Zheng, W., Huang, L., Huang, J., Wang, X., Chen, X., Zhao, J., Guo, J., Zhuang, H., Qiu, C., Liu, J., Liu, H., Huang, X., Pei, G., Zhan, G., Tang, C., Cheng, Y., Liu, M., Zhang, J., Zhao, Z., Zhang, S., Han, Q., Han, D., Zhang, H., Zhao, J., Gao, X., Wang, J., Ni, P., Dong, W., Yang, L., Yang, H., Xu, J. R., Zhang, G., and Kang, Z. 2013. High genome heterozygosity and endemic genetic recombination in the wheat stripe rust fungus. Nat. Commun. 4:2673. 